\title{
MULHER E CIÊNCIA: UMA RELAÇÃO POSSIVEL?
}

\author{
Lindamir Salete Casagrande ${ }^{1}$ \\ Juliana Schwartz ${ }^{2}$ \\ Marilia Gomes de Carvalho ${ }^{3}$ \\ Sonia Ana Leszczynski ${ }^{4}$
}

\begin{abstract}
RESUMO
Este artigo é o resultado de uma pesquisa cujo objetivo é identificar algumas mulheres que podem ser consideradas pioneiras nas ciências naturais. $O$ artigo está dividido em três partes, em que na primeira é apresentado um breve levantamento sobre a participação feminina nas ciências. Na segunda parte são apresentadas histórias de algumas mulheres que desenvolveram pesquisas no ramo das ciências em diversos periodos históricos. $\mathrm{Na}$ última parte, é feita uma análise da participação da mulher brasileira nas ciências. É possivel observar, com base no resultado desta pesquisa, que a mulher esteve presente no meio científico, participando de forma ativa no desenvolvimento das ciências.

Palavras-chave: Ciência; Mulheres; Participação Feminina nas Ciências; Pioneiras em Ciências Naturais.
\end{abstract}

\section{INTRODUÇÃO}

Este artigo tem como objetivo fazer um levantamento das mulheres que se destacaram nas ciências naturais e desta forma podem ser consideradas pioneiras em suas áreas de atuação. Observou-se, no decorrer da pesquisa, que osias cientistas da época não se dedicavam a uma única ciência, mas a vários ramos dela como química, física, matemática, astronomia e filosofia ao mesmo tempo.

Para o desenvolvimento desta pesquisa fez-se uma busca por dados históricos sobre personalidades femininas, porém encontrou-se dificuldades para localização das fontes. Percebeumse que a história da ciência não foi preservada de forma sistemática e, com isso, as informações sobre os/as grandes cientistas é de difícil acesso. Como este estudo tem o intuito de visibilizar as mulheres que participaram do desenvolvimento das ciências, as informações biográficas constituem-se de grande valia.

A presença da mulher nas ciências pode ser notada em diversos períodos históricos. Houve época em que as ciências eram produzidas no âmbito familiar e, neste caso, o acesso feminino era facilitado já que, com freqüência, mulheres eram iniciadas nas ciências por seus pais, maridos ou irmãos com a finalidade

1 Mestre em Tecnologia pelo Programa de Pós-Graduação em Tecnologia - PPGTE do Centro Federal de Educaçāo Tecnológica do Paraná - CEFET-PR, licenciada em matemática, especialista em Fundamentos da Matemática, pesquisadora do Grupo de Estudos e Pesquisas sobre Relações de

Gênero e Tecnologia - GeTec (www.ppgte.cefetpr.br/genero) e professora da UTFPR.

2 Mestre em Tecnologia pelo PPGTE/CEFET-PR, engenheira da computação e pesquisadora do GeTec.

3 Doutora em Antropologia Social, professora do PPGTE / CEFET-PR, coordenadora e pesquisadora do GeTec da UTFPR.

4 Doutora em Educação pela Universidade de lowa, professora do PPGTE / CEFET-PR, Assessora de Ações Acadêmicas e Projetos Sociais da UTFPR, e pesquisadora do GeTec da UTFPR. 
de auxiliá-los em suas pesquisas e descobertas científicas. Algumas demonstravam habilidade e amor às ciências tanto quanto (ou talvez mais que) seus mestres e, de assistentes, elas passavam a desenvolver pesquisas importantes, fazendo grandes descobertas que nem sempre thes eram atribuidas, pois, como trabalhavam junto com sua familia, os méritos eram dados ao pai, irmão ou marido, ou seja, ao 'homem da familia', A participação delas nas descobertas, na maioria das vezes, era sequer mencionada, permanecendo as mulheres na invisibilidade.

Com a formalização das ciências e a mudança dos laboratórios e observatórios do ambiente familiar para dentro das universidades, a participação da mulher ficou ainda mais limitada, pois o acesso delas à universidade não era permitido. Assim, durante pelo menos um século, elas não puderam desenvolver pesquisas científicas nem mesmo como auxiliares. Muitas universidades só passaram a admitir mulheres em seu quadro discente e docente no final do século XIX e início do século XX (SCHIENBINGER, 2001).

O fato da academia e da universidade imporem obstáculos para o ingresso das mulheres também pode ter sido uma das razões para o menor número delas em posições de destaque nas ciências. Outro fator limitante pode ter sido a escassez de exemplos de mulheres bem sucedidas em suas carreiras científicas. Londa Schienbinger (2001) argumenta que resgatar os feitos de grandes cientistas femininas faz-se necessário para criar exemplos para as meninas se encorajarem a seguir a carreira científica. Ela ressalta também a importância de mulheres que tenham realizado descobertas nas artes e nas ciências, pois a habilidade para estudar e aprender conteúdos científicos já conhecidos nem sempre representa grande feito.

Como ocorreu (e ainda ocorre) a relação da mulher com a ciência? As mulheres enfrentaram (ou enfrentam) dificuldades para seguir carreiras científicas? Existe um estilo feminino de se fazer ciência? Existem ramos da ciência masculinos e outros femininos? No próximo item tentar-se-á encontrar respostas para alguns destes questionamentos com o intuito de mostrar a participação e contribuição feminina ao meio científico.

\section{A PRESENÇA FEMININA NA CIÊNCIA: MITO OU REALIDADE?}

A participação feminina no meio científico tem enfrentado alguns problemas. O método científico, por exemplo, desvaloriza características tidas como femininas como a "subjetividade, cooperação, sentimento e empatia" (SCHIENBINGER, 2001, p. 24). Segundo Schienbinger (2001), julga-se que estas características deixam a pesquisa 'menos cientifica'. Muitos pensam que a mulher não tem capacidade para realizar pesquisas 'sérias' e relevantes. A autora aponta que "Kant [por exemplo] ensinava, entre outras coisas, que qualquer pessoa envolvida em atividade intelectual séria deveria ter barba" (SCHIENBINGER, 2001 , p. 138). Desta forma as mulheres não poderiam se envolver nessas atividades. Porém a história desmente esse ensinamento de Kant, visto que muitas mulheres têm desenvolvido pesquisas relevantes nos diversos ramos das ciências. 
A partir do século $X X$, quando elas obtiveram o direito de freqüentar a universidade, um número crescente de mulheres tem se envolvido em atividades cientificas, provocando, inclusive, o desenvolvimento de novas áreas da ciência.

Schienbinger (2001) considera que, não só a mulher, mas também as ciências devem mudar para que a participação feminina ocorra de forma adequada. "A ciência moderna é um produto de centenas de anos de exclusão das multieres, o processo de trazer mulheres para a ciência exigiu, e vai continuar a exigir, profundas mudanças estruturais na cultura, métodos e conteúdo da ciência" (SCHIENBINGER, 2001, p. 37). Entretanto, algumas áreas da ciência não se mostraram abertas para as mulheres e, por esse motivo, elas tiveram que modificar seu comportamento e sua postura para conseguirem ter acesso a essas ciências e serem reconhecidas por seus pares.

Considera-se que a forma de se estudar e desenvolver pesquisa em primatologia, por exemplo, foi revolucionada com a presença feminina. Porém, ainda neste campo, caracteristicas atribuidas como femininas são utilizadas para desvalorizar o trabalho da pesquisadora. Dizem, por exemplo, que "as mulheres são empáticas [...] e esta abordagem, portanto, é fácil para elas" (SCHIENBINGER, 2001, p. 36), ao se referir ao longo trabalho de uma pesquisadora na observação de macacos. Alguns pensadores consideram a paciência na espera pelos resultados, o pensamento holistico e o fato de estarem menos dispostas a aceitarem pontos de vista reducionistas como características das pesquisadoras ${ }^{5}$. Estudos apontam que cientistas norte-americanos (homens e mulheres) consideram que as mulheres mostram-se mais minuciosas, cuidadosas, detalhistas e que se dedicam a campos em que a competição é menos acirrada ${ }^{6}$. Este mesmo estudo indica que os cientistas consideram que a ciência deve ser de gênero neutro (SCHIENBINGER, 2001).

Schienbinger (2001) argumenta que não se deve incorrer no erro de pensar que há um 'estilo feminino' de fazer ciência, pois conforme o argumento da autora "as metas feministas na ciência não serão realizadas através da invocação de princípios dominados por clichês tirados de um mitico 'feminino perdido'" (SCHIENBINGER, 2001, p. 31). Ela considera a necessidade de se criar instrumentos de análise capazes de desenvolver a consciência critica de gênero em jovens cientistas de ambos os sexos.

A autora também defende a idéia de que as mulheres devem atuar nos mais diversos ramos da ciência, para que, assim como os homens, elas sejam pensadas e reconhecidas individualmente e não como um bloco com as mesmas expectativas e experiências. Deve-se levar em conta a multiplicidade de mulheres e o contexto em que estão inseridas. Para Donna Haraway "não existe nada no fato de ser 'mulher' que naturalmente una as mulheres. Não existe nem mesmo uma tal situação - 'ser' mulher" (HARAWAY, 2000, p. 52). O que vem a reforçar a teoria de defendida por Schienbinger.

Também não se deve pensar em ciência separada da sociedade e da cultura na qualestá sendo desenvolvida, pois, "só será possivel existirem relações não discriminatórias e não exploradoras dentro da ciência quando relações

5 Schienbinger cita os estudos de Linda e Laurence Fedigan.

6 O sociólogo Gerhard Sonnert e o fisico Gerald Holton realizaram pesquisa com 699 cientistas (Schienbinger, 2001). 
igualitárias caracterizarem a própria sociedade" (BERMAN, 1997, p. 248). A mudança de pensamento da sociedade é fundamental para o desenvolvimento mais democrático das ciências, em que homens e mulheres tenham as mesmas oportunidades de participação e crescimento. Para este estudo está sendo considerada apenas a questão de gênero, porém não se pode esquecer das questões de raça, classe, etnia, dentre outras que também permeiam o meio científico.

Ações governamentais têm facilitado o aumento do número de mulheres cientistas ${ }^{7}$. Porém o processo de mudança é lento e complexo. Já que um número maior de meninas interessadas em ciências, por exemplo, não significa um maior número de mulheres cientistas, e "compreender o choque histórico entre as culturas discrepantes da ciência e da feminilidade é crucial para entender o mal estar que muitas mulheres sentem no mundo da ciência profissional" (SCHIENBINGER, 2001, p. 42), o que chega a fazer com que algumas delas desistam de suas carreiras.

A cultura ocidental vê a mulher mais como receptora do conhecimento do que como geradora do mesmo, e os conhecimentos utilizados para entender a natureza e as necessidades humanas nem sempre são vistos como ciência. É o caso, por exemplo, do conhecimento das mulheres indígenas, da fabricação do pão, do tingimento de roupas e da tapeçaria que não são considerados ciência e, no entanto, representaram grande avanço científico em suas respectivas épocas e comunidades (SCHIENBINGER, 2001). Ângela Maria Freire de Lima e Souza (2003) considera que o acesso ao conhecimento de forma plena foi negado às mulheres por muitos séculos, por se considerar que elas não eram dotadas de razão. A elas "são destinados [...] certos saberes ligados ao oculto, aos mitos, aos saberes do cotidiano que nada têm em comum com a sistematização rígida e hierárquica da Ciência como instituição" (SOUZA, 2003, p. 120).

Vive-se em um mundo no qual a cultura androcêntrica rege as formas de conduta dos individuos. Desta forma estamos culturalmente predispostos a considerar as realizações masculinas como mais importantes que as femininas. Outra tendência é a de considerar que as realizações relevantes são 'obras de homens' e a descoberta de que a autora, inventora ou descobridora de uma nova ciência, técnica ou inovação é uma 'mulher' geralmente causa surpresa (MORENO, 1999).

Alguns campos do conhecimento se mostraram mais abertos à presença feminina e foram mais desenvolvidos por mulheres, outros por homens. Por exemplo, a astronomia sempre se mostrou um bom campo para a atuação feminina mesmo que as mulheres atuassem como ajudantes e em funções secundárias. Por outro lado, a matemática e a física são, ainda hoje, resistentes ao acesso das mulheres (SCHIENBINGER, 2001).

Outro empecilho imposto à maior participação feminina nas ciências é a imagem do cientista como um ser solitário que passa o tempo todo trancado em seu laboratório, que não tem vida social tampouco familiar. Souza argumenta que a mulher tem mais responsabilidade com a familia e desta forma "ser mulher e ser cientista representam para muitas delas não a complexidade natural de uma vida plena de realizações" (2003, p. 122) como para os homens, mas "a 
frustração por não poder realizar plenamente suas ambições profissionais, ou não ter possibilidade de realizar aquilo que a sociedade espera de todas as mulheres, quer elas desejem quer não, a maternidade." (SOUZA, 2003, p. 122).

Durante muito tempo questionou-se se a mulher teria capacidade para desenvolver ciência, porem há que se convir que "sem formação apropriada e acesso a bibliotecas, instrumentos e redes de comunicação é dificil para qualquer um - homem ou mulher - fazer contribuições significativas ao conhecimento" (SCHIENBINGER, 2001, p. 59). Souza (2003) considera como principal desafio para as mulheres provar que são tão capazes quanto os homens de realizar qualquer atividade intelectual, o que vem ocorrendo, pois o número de mulheres é crescente em todos os ramos da Ciência, inclusive naqueles tidos como masculinos. Desta forma, a participação feminina nas ciências é cada vez mais consolidado, passando de algumas 'aventureiras' para um número significativo de mulheres cientistas.

A seguir serão relacionados os nomes de algumas mulheres que conseguiram desenvolver pesquisa cientifica relevante, bem como seus principais feitos apesar dos obstáculos e dificuldades que tiveram que enfrentar.

\section{ALGUMAS PIONEIRAS EM CIÊNCIAS NATURAIS}

Comumente ouve-se falar que as mulheres têm pouca habilidade para estudos matemáticos. Apesar desta idéia nunca ter sido cientificamente comprovada, ainda assim ela persiste e é reforçada (MORENO, 1999). Por exemplo, observando os teoremas e regras que se aprende na escola nota-se que todos levam o sobrenome de seus descobridores e não é possível identificar nenhuma mulher, já que pelo sobrenome não se pode perceber se a pessoa é homem ou mulher. Interpreta-se que o descobridor é homem, pois a cultura do androcentrismo leva a pensar assim (MORENO, 1999). Como identificar se atrás do sobrenome dos cientistas não há nenhuma mulher?

Ao lançar um olhar mais atento à história das ciências é possivel encontrar mulheres que dedicaram suas vidas aos estudos científicos e fizeram descobertas significativas dentro de sua área de conhecimento e para a sua época.

Essas mulheres enfrentaram muitas dificuldades para prosseguirem em suas carreiras, dificuldades que iam desde a proibição dos pais até a falta de acesso à universidade e desta forma ao estudo sistematizado. As mulheres que serão apresentadas a seguir ilustram e demonstram a presença feminina no desenvolvimento das ciências naturais, porém não foram as únicas. Devido a sua persistência, brilhantismo e genialidade, elas conseguiram inscrever seusnomes na história. Em sua maioria, autodidatas, uma vez que não Ihes era permitida uma formação acadêmica, ainda assim elas contribuíram de forma impar para o desenvolvimento da ciência.

HIPATIA DE ALEXANDRIA (370-415)

Nascida na Grécia, esta filósofa e matemática foi "a primeira mulher da qual nos chegou registro de ter trabalhado e escrito em matemática" (MORAIS FILHO, 1996, p. 3). É importante frisar que foi a primeira mulher a conseguir inscrever seu nome na história, e isso não significa que tenha sido a primeira a 
se interessar pelos estudos matemáticos. Filha do também matemático Theon de Alexandria, Hipatia chamava a atenção por sua beleza e cultura. Foi fundadora de uma escola de filosofia em Atenas onde se estudava a filosofia de Platão e Aristóteles (TUDO, 1977).

Daniel C. Morais Filho (1996) argumenta ainda que, apesar de nenhum dos escritos de Hipatia ter sido preservado, acredita-se que eles trataram sobre as Secções Cônicas de Apolônio, a Aritmética de Diofanto e também sobre o Almagesto. A ela também é atribuida a invenção de alguns aparelhos mecânicos, além de escrever uma tábua de astronomia. É possivel perceber que seu conhecimento era amplo e perpassava diversos ramos da ciência, fato comum aos cientistas de sua época.

Reconhecida filósofa, atingiu o cargo de diretora da Escola Neoplatônica de Alexandria e foi uma das primeiras mulheres a ser admitida como professora no Museu de Alexandria.

Sua morte aconteceu de forma trágica. Mesmo com seu brilhantismo e reconhecimento alcançado. Hipatia foi acusada de se recusar a mediar a paz entre o poder político e o religioso, que em sua época viviam em constante conflito. Isso foi suficiente para despertar a fúria de um grupo de fanáticos que a atacou, despiu e esquartejou seu corpo (MORAIS FILHO, 1996).

A morte de Hipatia deixou uma lacuna na matemática e pôs fim "à gloriosa fase da matemática Alexandrina" (MORAIS FILHO, 1996, p. 4).

\section{MADAME DU CHÂTELET (1706-1749)}

Nascida na França, em uma família nobre, Gabrielle Emilie Le Tonnelier de Bréteuil casou-se aos dezenove anos com o Marquês de Châtelet, e desde então, passou a ser conhecida como Madame du Châtelet.

Desde muito cedo Emilie recebeu educação esmerada e tinha autorização dos pais para freqüentar o salão onde eram recebidas pessoas influentes da época. Dentre eles o cientista Voltaire, com quem, mais tarde Emilie estabeleceu uma forte relação intelectual e amorosa. Aos 17 anos já era versada em latim, italiano, inglês e espanhol, além de demonstrar interesse por filosofia. Porém, "as suas grandes paixões seriam a Matemática e a Metafísica" (TOSI, 1998, p. 389).

Mme. du Châtelet desenvolveu junto com Voltaire os Eléments de la Philosophie de Newton. A publicação foi feita por Voltaire e ele reconheceu aparticipação de Emilie (Minerva da França, como ele a chamava) em uma carta ao rei na qual dizia "Minerva ditava e eu escrevia" (VOLTAIRE citado por TOSI, 1998 , p. 390), entretanto, publicamente, manteve-a na invisibilidade.

Emilie dedicou seus estudos a investigar a natureza do fogo, sobre o que redigiu uma dissertação e publicou-a à revelia de Voltaire. Redigiu também as Institutions de Physique. Este tratado foi muito importante para a recuperação da obra de Emilie, pois sua semelhança com os Eléments de la Philosophie de Newton levou "o historiador Ira $\mathrm{O}$. Wade a descobrir a influência de Mme. du Châtelet na obra de Voltaire" (TOSI, 1998, p. 390). Seu principal trabalho foi a tradução para o francês da obra mais importante de Newton, a Principia Mathematica, que permanece até hoje como a tradução francesa padrão daquela obra (SCHIENBINGER, 2001). 
Nascida em Milão, precocemente iniciou seus estudos estimulada por seu pai, professor de matemática na Universidade de Bolonha. Ela participava de reuniões organizadas por ele que contava com a presença de acadêmicos, cientistas e intelectuais renomados. Além de conhecer a matemática de sua época, Agnesi era poliglota, versada em Fisica e em outros ramos da ciência. Aos 20 anos, publicou sua primeira obra, um tratado escrito em latim, Propositiones Philosophicae, no qual mostra a sua forma de pensar e defende o direito à educação superior às mulheres, o que até então era negado (MORAIS FILHO, 1996).

Após a publicação, decidiu dedicar-se à vida religiosa, mas foi impedida por seu pai. Passou, então, os próximos 10 anos desenvolvendo estudos matemáticos e ao final desse periodo Agnesi publicou sua principal obra, Instituzioni Analitiche ad uso della Gioventú. Esta obra foi reconhecida como o primeiro tratado de cálculo escrito de forma didática. Em 1775 a Academia Real de Ciências da França resolveu publicá-lo também em francês. Abrilhante italiana conseguiu transpor os limites de seu pais com sua obra.

Embora sua notoriedade tenha se espalhado rapidamente Agnesi não chegou a assumir uma cadeira na universidade, apesar de ter sido aceita como membro pela Academia de Ciência de Bologna, pois com a morte de seu pai Agnesi pode então, seguir o caminho que havia escolhido e dedicar-se à carreira religiosa. Ela morreu aos 81 anos de idade.

Hoje a única lembrança de Agnesi è uma curva de terceiro grau, 'Curva de Agnesi', cuja autoria é comumente atribuida a um homem.

\section{SOPHIE GERMAIN (1776-1831)}

Nasceu em Paris, em uma rica familia. Com a Revolução Francesa Sophie que tinha apenas 13 anos, teve que ficar praticamente confinada na biblioteca da familia, quando então teve seu primeiro contato com a matemática. Dentre os muitos livros do acervo ela leu a biografia de Arquimedes e ficou impressionada com o modo como ele foi assassinado". "Esse fato a fascinou de tal maneiraque decididamente optou pela Matemática" (MORAIS FILHO, 1996, p. 6). Ao decidir ingressar na carreira científica, Sophie, que já havia se tornado autodidata em grego e latim e estudado a obra de Newton e Euler, encontrou na oposição de seus pais um grande obstáculo para o andamento de seus estudos.

Eles fizeram de tudo para persuadir a filha a não seguir a carreira matemática: tiraram a luz de seu quarto, confiscaram o aquecedor [...], mas Sophie, persistente, continuava estudando à luz de velas, escondida embaixo dos cobertores. Sua determinação foi tanta que derrotou a oposição dos pais, que acabaram liberando seu acesso aos livros de matemática da família (MORAIS FILHO, 1996, p. 6).

8 Arquimedes foi assassinado durante o cerco romano a Siracusa enquanto desenhava figuras geométricas na areia e, absorto em seus pensamentos, não percebeu a aproximação do inimigo (MORAIS FILHO, 1996). 
Apesar de não poder freqüentar a recém-inaugurada École Polythecnique de Paris por 'ser mulher', Sophie se disfarçou de homem e conseguiu algumas anotações de um curso ministrado por Lagrange na École e passou a se corresponder com ele usando o pseudônimo de M. Le Blanc. Com o mesmo pseudônimo também manteve correspondência com Gauss, que ficou surpreso quando soube que seu correspondente na França era uma mulher. Em uma carta a Sophie, Gauss diz:

\begin{abstract}
Mas quando uma pessoa pertencente ao sexo no qual, de acordo com nossos costumes e preconceitos, é forçada a enfrentar infinitamente mais dificuldades do que os homens para familiarizar-se com essas pesquisas dificilimas, e consegue, com êxito, penetrar nas partes mais obscuras delas, tendo para isso, que superar todas essas barrejras, então essa pessoa tem, necessariamente, a mais nobre coragem, os mais extraordinários talentos e uma genialidade superior (GAUSS, citado por MORAIS FILHO, 1996, p. 2).
\end{abstract}

Sua principal contribuição à matemática foi "a noção de curvatura média de uma curva oblíqua em um ponto" (GRANDE ENCICLOPÉDIA LAROUSSE CULTURAL, 1998, p. 2699) que é utilizada até os dias atuais. Pesquisou também a elasticidade dos corpos e recebeu o Prêmio das Ciências Matemáticas da Academia de Ciências de Paris, em 1816. Sophie não se dedicou somente à matemática, teve incursões também pela física, química, geografia, história, psicologia e filosofia, porém ela morreu antes que Gauss conseguisse que a Universidade de Göttingen lhe concedesse um doutorado honoris causa (MORAIS FILHO, 1996).

Sophie pode ser considerada a primeira mulher a fazer um trabalho inédito em matemática, apesar do mesmo conter algumas falhas devido ao seu autodidatismo e ao isolamento do meio matemático, pois seu convívio com Lagrange, Gauss e outros matemáticos deu-se somente através de correspondência (MORAIS FILHO, 1996).

\title{
MARY FAIRFAX GREIG SOMERVILLE (1780-1872)
}

Nascida na Escócia, também alcançou notório saber e reconhecimento no mundo acadêmico. Seu interesse pela matemática teve início quando, aos 13 anos, viu em uma revista de moda feminina um problema de álgebra elementar ${ }^{9} e$ ao buscar saber de que se tratava descobriu que era uma espécie de aritmética que usava letras em vez dos números (MORAIS FILHO, 1996). Então, por acaso, teve conhecimento dos Elementos de Euclides. Porém, foi difícil conseguir um exemplar do livro, pois naquela época, "não era decente para uma mulher chegar numa livraria e comprar um livro de matemática" (MORAIS FILHO, 1996, p. 8). Tal fato evidencia que o preconceito e a discriminação para com a mulher já existiam.

Somerville, no entanto, enfrentou todos os obstáculos, inclusive a oposição de seu pai que não concordou com seus novos 'estudos masculinos', o que

9 Não foi possivel entender o motivo da publicaçăo de um problema de álgebra em uma revista feminina, visto que na época, as mulheres não podiam estudar matemática. 
dificultou sua iniciação nos estudos matemáticos. Ao conseguir os exemplares dos Elementos de Euclides e da Álgebra de Bonnycastle com a ajuda de seu irmão mais novo, pode enfim iniciar seus estudos, que não ficaram restritos a álgebra.

Ela dedicou-se a estudar fisica e astronomia além de matemática superior. Mais tarde, após publicar vários artigos, resultado de seus estudos em física experimental, ela foi admitida por sociedades cientificas de vários paises, tendo sido a primeira mulher admitida na Sociedade Real Inglesa de Astronomia e recebeu da Sociedade Real Inglesa de Ciências uma homenagem na forma de um busto que foi exposto no hall do prédio da Sociedade. Porém, Somerville jamais pode vê-lo, já que as mulheres eram impedidas de entrar lá (MORAIS FILHO, 1996). Seu talento era reconhecido e exaltado, porém não quebrava o protocolo e o preconceito da época.

Somerville passou o resto de sua vida elaborando artigos científicos e quando a morte chegou aos 92 anos ainda se dedicava aos estudos matemáticos.

MARIE CURIE (1867-1934)

Nascida em Varsóvia na Polônia, recebeu o nome de Marya Sklodowska. Após ter concluido o ginásio e não ter sido aceita na universidade, em 1883, "associou-se à Universidade Flutuante que era feminista, clandestina e subversiva" (SIMMONS, 2002, p. 170). Em 1891, mudou-se para Paris onde foi aceita na Universidade de Paris. Foi a primeira mulher graduada em física pela Sorbonne e um ano depois formou-se também em matemática. Em Paris, casouse com o cientista Pierre Curie e adaptou seu nome para a lingua francesa, passando a assinar Marie Curie.

Desenvolveu pesquisa com seu marido e o casal conquistou junto com Becquerel o Prêmio Nobel em 1903 pela descoberta da radioatividade. É importante ressaltar que, a participação de Marie nas pesquisas que resultaram no prêmio Nobel não foi aceita sem resistências pela academia. Muitos cientistas contemporâneos interpretaram o fato de Pierre reconhecer que sua esposa trabalhou lado-a-lado com ele no desenvolvimento da pesquisa, simplesmente como uma prova de amor. Para eles, era como se o marido tivesse 'dividido' o prêmio com a esposa para demonstrar seu sentimento por ela (SCHIENBINGER, 2001). John Simmons considera que "é certamente um crédito para Pierre, o intenso esforço que fez em favor de sua mulher, pois somente ele fora considerado como candidato ao prêmio" (SIMMONS, 2002, p. 172). Após a morte de Pierre, Marie foi convidada à cadeira de professora em substituição ao marido e aoassumi-la, tornou-se a primeira professora da Sorbonne (SIMMONS, 2002).

Marie descobriu os elementos químicos radioativos polônio (nome dado em homenagem a seu pais de origem) e rádio e, em 1911, recebeu o segundo Prêmio Nobel, desta vez em química, por ter isolado o rádio e "transformou-se na única pessoa a ganhar por duas vezes o Prêmio Nobel" (HART, 2001, p. 572). Apesar desses feitos para a ciência, Marie Curie não foi considerada po 
Michael H. Hart ${ }^{10}$ uma das 100 maiores personalidades da história da humanidade, pois este considera que "embora sejam realizações admiráveis, não apresentam excepcional importância para a teoria cientifica" (HART, 2001, p. 572). O autor considera que a fama de Marie deve-se mais ao fato de ela ser mulher do que propriamente pelos seus feitos científicos. "Sua carreira demonstrou da maneira mais clara possivel, que uma mulher é capaz de fazer pesquisa científica de alta qualidade" (HART, 2001, p. 571). Esta frase pode indicar que, para ser considerada capaz de grandes realizações e para ser aceita pelos seus pares, a mulher tinha que prová-lo e comprová-lo através de feitos excepcionais.

Marie morreu de leucemia, provavelmente causada pela excessiva exposição à radiação sem cuidados, pois os Curie não conheciam os perigos da radioatividade (MORTACCIA e GUTIÉRREZ, 2003).

\section{OUTRAS CIENTISTAS IMPORTANTES}

Neste item serão nomeadas outras mulheres que desenvolveram pesquisas em ciências e das quais se tem poucas informações. São elas: a química Mariev Meurdarc ${ }^{11}$, autora do primeiro livro de química escrito por uma mulher, publicado pela primeira vez em 1665-66; a astrônoma Maria Winkelmann (1670-1720), que fez a primeira descoberta da Academia de Berlim, um cometa; a astrônoma Caroline Herschel (1750-1848), descobridora de oito cometas; a física e matemática Laura Bassi (1711-1778), primeira professora da Universidade de Bologna nomeada em $1732^{12}$ e autora de 49 proposições publicadas por ocasião de seu doutorado.

Após a breve explanação sobre o panorama da participação da mulher no cenário científico mundial e apresentação da história dessas mulheres que se destacaram nas ciências em suas épocas, resta alguns questionamentos sobre a situação da mulher cientista brasileira. As mulheres brasileiras têm enfrentado dificuldades para seguir carreiras científicas? No Brasil, existem áreas do conhecimento com predominância feminina ou masculina? A participação da mulher nas ciências exatas e nas engenharias tem aumentado nos últimos anos? É em busca de resposta para estes questionamentos que será desenvolvido o próximo item.

Hart publicou em 2001 um livro com as 100 personalidades que ele considerou mais influentes na história da humanidade. Dentre elas encontramos apenas duas mulheres, ambas rainhas. Näo conseguimos o ano de seu nascimento e morte.

12 Periodo em que a maioria das universidades não aceitava mulheres como discente ou docente. A Itália era um país que tinha tradição em apresentar mulheres em seus quadros universitários, diferentemente dos outros países Europeus. 
Vimos em item anterior que as mulheres encontraram (e ainda encontram) obstáculos para sua participação nas ciências, independentemente do seu país de origem.

No Brasil, a inserção feminina no meio científico não provocou mudanças nas ciências, principalmente nas ciências naturais, pois "os movimentos feministas desde o final da década de 1970 , no Brasil, não incorporaram ou geraram qualquer tipo de contingente expressivo de mulheres que se dedicassem ou viessem a se dedicar às ciências naturais e exatas" (LOPES, 1998, p. 364).

Uma das pioneiras nas ciências no Brasil foi a zoóloga e feminista Bertha Lutz (1894-1976), porém não se tem pesquisas biográficas centradas em sua participação como pesquisadora no Museu Nacional. Os estudos ${ }^{13}$ existentes são voltados para a participação política de Bertha, nos quais ela defendia a emancipação feminina e o direito ao voto para as mulheres (LOPES, 1998).

Lopes (1998) chama atenção para a negação da existência de atividades cientificas no Brasil nos séculos passados. Sendo a história do País constituída de apenas 5 séculos, a história das ciências é ainda mais recente e de pouca tradição. A mulher brasileira teve acesso à universidade no ano de $1879 \mathrm{e}$, conseqüentemente, ao meio científico somente após está data.

Como as informações sobre as pioneiras brasileiras nas ciências são de difícil acesso, pois, no Brasil, não se tem uma área que concentre as publicações relacionadas a gênero e ciência (LOPES, 1998), optou-se, para a realização deste estudo, pela análise da participação feminina nas ciências nos dias atuais.

Neste sentido encontramos a obra de Fanny Tabak (2002), na qual ela faz uma análise da participação da mulher, como docente e discente, em duas universidades brasileiras ${ }^{14}$. A liberação do acesso à universidade, possibilitou que mulheres seguissem carreira de nivel superior e desta forma aumentou a participação feminina nas ciências (TABAK, 2002), porém dados do CNPq (Conselho Nacional de Desenvolvimento Cientifico e Tecnológico) mostram que o número de mulheres pesquisadoras em ciências exatas e engenharias (ciências hard) é bem inferior do que o de homens nas mesmas áreas. Elas estão lá, em número menor, mas presentes nesse universo 'masculino'. Todavia, a maior participação feminina se dá nas ciências humanas e sociais (ciências soft) (QUADRO 1). Tabak argumenta ainda que os homens se adaptam melhor às ciências tidas como femininas do que as mulheres às ciências tidas como masculinas.

Analisando os dados do QUADRO 1, temos algumas informações que confirmam a afirmação de Tabak com relação as áreas do conhecimento dominadas por homens e/ou mulheres. É o caso das Ciências Exatas e da Terra nas quais as mulheres representam pouco mais de $30 \%$ dos pesquisadores com mestrado e doutorado e das Engenharias e Ciências da Computação em que o percentual é ainda menor, fica em torno de $23,8 \%$. Já nas Ciências Humanas a participação feminina chega a quase $60 \%$ e em Lingüística, Letras e

13 Ver os estudos de Rachel Sohiet e Branca Moreira Alves.

14 Pontificia Universidade Católica do Rio de Janeiro e Universidade Federal do Rio de Janeiro. 
Artes este percentual ultrapassa os $67 \%$ dos pesquisadores com mestrado e doutorado. Esses dados mostram de forma clara que a participação feminina em determinadas áreas ainda é baixa, porém, somente com base neles, não se pode afirmar quais os motivos que direcionam as mulheres para uma área e não para outras. Para isso há necessidade de mais pesquisa.

\section{Quadro 1 - NÚMERD DE PESQUISADORES POR TITULAÇÃO MÁXIMA E SEXO SEGUNDO GRANDE ÁREA PREDOMINANTE DO GRUPO}

\begin{tabular}{l|r|r|r|r|r|r|r|r|r}
\hline \multicolumn{2}{c|}{} & \multicolumn{3}{c}{ Mestrado } & \multicolumn{3}{c}{ Doutorado } & \multicolumn{3}{c}{ Porcentagem } \\
\hline & $\begin{array}{r}\text { Total } \\
\text { geral }\end{array}$ & Masc. & Fem. & Não & Masc. & Fem. & $\begin{array}{r}\text { Năo } \\
\text { inf. }\end{array}$ & $\begin{array}{r}\text { Masc. } \\
\%\end{array}$ & $\begin{array}{r}\text { Fem. } \\
\%\end{array}$ \\
\hline Ciências Humanas & 9.133 & 1.269 & 2.360 & 0 & 2.481 & 3.022 & 1 & 41 & 59 \\
Ciências Sociais Aplicadas & 4.875 & 956 & 1.065 & 0 & 1.698 & 1.156 & 0 & 54,4 & 45,6 \\
Ciências da Saúde & 8.743 & 814 & 1.971 & 0 & 2.967 & 2.990 & 1 & 43,2 & 56,8 \\
Engenharias e & & & & & & & & & \\
Ciências da computação & 8.439 & 1.616 & 706 & 0 & 4.820 & 1.297 & 0 & 76,2 & 23,8 \\
Lingüistica, Letras e Artes & 2.483 & 245 & 618 & 0 & 555 & 1.065 & 0 & 32,2 & 67,8 \\
\hline Totais & 55.958 & 7.596 & 8.999 & 0 & 23.555 & 15.804 & 4 & 55,7 & 44,3 \\
\hline
\end{tabular}

Fonte-Censo 2002 do CNPQ.

Tabak (2003) argumenta que o Brasil, um pais que encontra-se em desenvolvimento, oferece muita resistência à participação das mulheres no meio científico e tecnológico. A autora considera que "o esforço por desenvolver o país em ritmos mais acelerados e superar o atraso ainda visivel em muitas áreas sociais, deixa de contar com a contribuição da inteligência e da competência de milhares de mulheres" (TABAK, 2003, p. 18). Ela ressalta que um país que quer se aproximar dos países desenvolvidos no que tange a ciência e tecnologia "não pode se dar ao luxo de prescindir da incorporação de milhares e milhares de mulheres que venham a contribuir com seu talento e sua inteligência" (TABAK, 2003 , p. 18) para o desenvolvimento do país. A limitação da participação das mulheres no meio científico brasileiro se traduz no desperdiço de capacidade intelectual que poderia ser utilizada para o desenvolvimento de conhecimentos que poderiam se empregados para diminuir as desigualdades sociais (TABAK, 2003).

Quanto à produção científica, Lea Velho e Elena Leon (1998) realizaram um estudo em quatro departamentos da UNICAMP (Universidade Estadual de Campinas) e mostram que a produção cientifica de mulheres é menor que a de homens que ocupam cargos equivalentes. As autoras apontam obrigações familiares como fator limitante para uma maior produção científica feminina 
naqueles departamentos. A maternidade e a paternidade requerem dedicação diferente da mulher e do homem, normalmente a mulher tem que dispensar mais tempo para cuidar da prole, o que a afasta de sua carreira por algum tempo. A necessidade de dedicação em tempo integral à pesquisa também se apresenta como obstáculo para que mais mulheres sigam carreiras científicas. $\mathrm{O}$ estudo aponta que elas preferem ter mais tempo para a família e não estão dispostas a passar o tempo todo dentro de um laboratório realizando experimentos.

Pode-se perceber que a relação Mulher-Ciência no Brasil não difere muito dos demais países. A inserção feminina no meio científico e a 'permissão' para as mulheres freqüentarem a universidade ocorreu quase na mesma época que nos demais países, final do século XIX. Porém, ainda é oportuno se fazer alguns questionamentos. Quem foram as pioneiras em ciências no Brasil? A que ciência elas se dedicaram? Quais os obstáculos por elas enfrentados? As respostas a estes questionamentos não serão objeto deste artigo, pois para obter tais respostas há necessidade de realizar uma pesquisa mais aprofundada.

\section{CONSIDERAÇÕES FINAIS}

Com base nas histórias de vida destas cientistas, observa-se que as mulheres enfrentaram mais obstáculos para o acesso ao meio científico do que os homens. A mulher não tinha autonomia para a escolha de sua carreira, dependia da aprovação familiar, do estímulo e aceitação de uma figura masculina da família, além de ter que superar as discriminaçõeus existentes na sociedade da época. Percebe-se também a invisibilidade feminina, claramente evidente quando apenas Pierre Curie foi considerado pela academia como candidato ao Prêmio Nobel, sendo que o casal, Pierre e Marie, desenvolveu em conjunto a pesquisa sobre a radioatividade.

No período em que as ciências eram desenvolvidas no ambiente familiar, a mulher não só tinha acesso às pesquisas como era incentivada a auxiliar aos homens das familias que se dedicavam às ciências. Porém, depois que o trabalho científico passou a ser desenvolvido no ambiente universitário, as mulheres tiveram seu acesso restrito e não puderam mais contribuir tão significativamente para o desenvolvimento das ciências. Percebe-se aqui a rigida divisão dos papéis masculinos e femininos nas épocas aqui representadas que limitava a mulher às tarefas domésticas, na esfera privada da família, enquanto aos homens cabiam as atividades da esfera pública.

Ao enfrentar oposições e barreiras para seguir carreira científica, as mulheres foram obrigadas a encontrar estratégias para transgredir as regras e se dedicar às ciências. A vida de Sophie Germain representa um significativo exemplo deste fato.

A discriminação contra a mulher se faz notar nos diversos períodos históricos. A morte trágica de Hipatia, o fato de Sophie Germain ter que se esconder atrás de um pseudônimo masculino, de Somerville não poder comprar livros de matemática e nem receber a sua homenagem na Sociedade Real Inglesa de Ciências e de Marie Curie não ser indicada ao Prêmio Nobel, bem como o fato de Hart não considerar suas descobertas relevantes para a história científica são exemplos dessa discriminação de gênero. Essas mulheres foram persistentes 
o suficiente para superar os obstáculos que Ihes foram impostos, porém, quantas outras foram impedidas de prosseguirem na carreira científica? O que aconteceu com as 'cientistas em potencial' afastadas do meio científico? Provavelmente ficaram na invisibilidade e no anonimato e tiveram seus anseios por conhecimento frustrados.

As dificuldades que as mulheres, em determinadas épocas, enfrentaram para ter acesso ao conhecimento sistematizado, à universidade e aos livros podem justificar o múmero reduzido de mulheres que se destacaram nas ciências, porém estas não foram as únicas causas. Há a necessidade de realização de pesquisas mais aprofundadas para definir a natureza das dificuldades encontradas por elas, e como elas se manifestaram nestes diferentes contextos históricos e sociais.

Em se tratando de Brasil, a participação feminina nas ciências tem aumentado nos últimos anos e esta participação se dá principalmente nas ciências tidas como soft. Não é possivel afirmar com absoluta certeza qual ou quais os motivos para a menor participação feminina nas ciências consideradas hard. Pode ser pela dificuldade no acesso a tais ciências; pela socialização diferenciada ofertada a meninos e meninas que podem induzir os jovens de ambos os sexos a seguirem determinadas carreiras e não outras; pela preferência das mulheres por algumas áreas em detrimento de outras; ou pela união de vários fatores. Para uma afirmação mais precisa faz-se necessário realizar pesquisa com objetivo de identificar essas causas.

Este estudo está baseado em dados históricos e relata as condições em que as cientistas pioneiras realizaram suas pesquisas. Os obstáculos encontrados por elas eram próprios de sua época, porém observa-se que ainda hoje as mulheres encontram dificuldades para sua participação no campo científico. Entretanto, tudo indica que nos dias atuais essas dificuldades são menores, o que não dispensa a necessidade de estudos para saber como vem ocorrendo o acesso e a permanência delas na ciência.

Os exemplos das pioneiras citadas ilustram que a participação feminina sempre existiu nesse fechado campo das ciências. A mulher sempre participou da construção da história, ela apenas não foi 'vista' pelos historiadores que, pertencentes a um mundo dominado pela cultura androcêntrica, deixaram à margem importantes figuras femininas que ajudaram a construir a história científica da humanidade.

Assim, respondendo a pergunta título deste artigo, afirmamos que a relação da mulher com a ciência não só é possível como sempre existiu ao longo da história da humanidade.

\section{REFERÊNCIAS BIBLIOGRÁFICAS}

BERMAN, Ruth. Do dualismo de Aristóteles à dialética materialista: a transformação feminista da ciência e da sociedade. In: JAGGAR, Alison M. e BORDO, Susan R. Gênero, corpo, conhecimento. Rio de Janeiro: Record, Rosa dos Tempos, 1997, p. 241-275.

CNPq. Censo 2002 do Conselho Nacional de Desenvolvimento Científico e Tecnológico. Disponivel em: <http://www.cnpq.br>. Acesso em 20 de maio de 2003.

Grande Enciclopédia Larousse Cultural. São Paulo: Nova Cultural, 1998, v.11. p. 2699. 
HARAWAY, Donna. Manifesto ciborgue: ciência, tecnologia e feminismo-socialista no final do século XX. In: SILVA, Tomaz Tadeu da (org.). Antropologia ciborgue: as vertigens do pós-humano. Belo Horizonte: Autêntica, 2000, p. 37-130.

HART, Michael H. "Marie Curie", In: As 100 maiores personalidades da história: uma classificação das pessoas que mais influenciaram na história. Rio de Janeiro: DIFEL, 2001, p. $571-572$.

LOPES, Maria Margareth. "Aventureiras' nas ciências: refletindo sobre gênero e história das ciências naturais no Brasil". Cadernos Pagu, Campinas, n. 10, 1998, p. 345-368.

MORAIS FILHO, Daniel. C. "As mulheres na matemática". Revista do Professor de Matemática, $n^{\circ}$. 30, 1996, p. 2-9.

MORENO, Montserrat. Como se ensina a ser menina: o sexismo na escola. São Paulo: Moderna, 1999.

MORTACCIA, Maria e GUTIÉRREZ, Javiera. "Madame Curie heroína da dor": In: Corpos frágeis mulheres poderosas. Rio de Janeiro: Ediouro, 2003, p. 83-99.

SCHIENBINGER, Londa. O feminismo mudou a ciência? Bauru: EDUSC, 2001.

SIMMONS, John. Marie Curie \& a Radioatividade. In: Os 100 maiores cientistas da história: uma classificação dos cientistas mais influentes do passado e do presente. $2^{a}$ ed. Rio de Janeiro: DIFEL, 2002. p.168-174.

SOUZA, Ângela Maria Freire de Lima e. A construção da identidade da mulher cientista. In: FAGUNDES, Tereza Cristina Pereira Carvalho (org.). Ensaios sobre identidade e gênero. Salvador: Helvécia, 2003.

TABAK, Fanny. O laboratório de Pandora: estudos sobre a ciência no feminino. Rio de Janeiro: Garamond, 2002.

TABAK, Fanny. Gênero, conhecimento, ciencia e poder. In: CARVALHO, Maria Eulina P. de e PEREIRA, Maria Zuleide da C. (orgs.) Gênero e educação: múltiplas faces. João Pessoa: Universitária, 2003, p. 15-32.

TOSI, Lucia. Mulher e Ciência:A revolução científica, a caça às bruxas e a ciência moderna. Cadernos Pagu, Campinas, n. 10, 1998. p. 369-397.

TUDO. Dicionário Enciclopédico llustrado. São Paulo: Abril Cultural, 1977, p. 666.

VELHO, Lea e LEON, Elena. A construção social da produção cientifica por mulheres. Cadernos Pagu, Campinas, n. 10, 1998, p. 309-344. 